\title{
Zymosan attenuates melanoma growth progression, increases splenocyte proliferation and induces TLR-2/4 and TNF-a expression in mice
}

Mehdi Taghavi ${ }^{1}$, Esmaeil Mortaz ${ }^{2,3,4^{*}}$, Alireza Khosravi ${ }^{1}$, Ghasem Vahedi ${ }^{1}$, Gert Folkerts ${ }^{3}$, Mohammad Varahram ${ }^{5}$, Mehdi Kazempour-Dizaji ${ }^{5}$, Johan Garssen ${ }^{3,6}$ and Ian M. Adcock ${ }^{7}$

\begin{abstract}
Background: Melanoma is one of the most common types of skin malignancies. Since current therapies are suboptimal, considerable interest has focused on novel natural-based treatments. Toll-like receptors (TLRs) play an important role in evoking innate immunity against cancer cells. Zymosan, a known TLR-2 agonist, is a glucan derived from yeast cell walls with promising immunomodulatory effects. The aim of this study was to evaluate whether Saccharomyces cerevisiaederived zymosan-modulated skin melanoma progression by regulation of TLR-2 and TLR-4 expression in peritoneal macrophages and serum TNF-a level.

Methods: Male C57BL/6 mice were divided into four groups: i) zymosan-treated (Z), ii) Melanoma-bearing mice (M), iii) Melanoma-bearing mice treated with zymosan (ZM) and iv) a healthy control group (negative control). 15 days after melanoma induction, mice were injected i.p. with zymosan $(10 \mu \mathrm{g})$ daily for 4 consecutive days. Mice were $\mathrm{CO}_{2}{ }^{-}$ euthanized and serum TNF-a level, TLR-2 and TLR-4 expression in peritoneal macrophages and tumor growth measured. Splenocytes were treated ex-vivo with zymosan to determine viability and proliferation.

Results: Tumor weight significantly decreased following therapeutic dosing with zymosan $(P<0.05)$. This was associated with zymosan-induced upregulation of TLR-2, TLR-4 and TNF-a MRNA in peritoneal macrophages and enhanced serum TNF-a levels $(P<0.05)$. Splenocyte number and viability were increased in a concentrationdependent manner by zymosan.

Conclusions: Our study suggests that zymosan-induced upregulation of TLR-2, TLR-4 and TNF-a gene expression and of TNF-a release; together with increased level of lymphocyte proliferation may play a role in the inhibition of melanoma progression.
\end{abstract}

Keywords: TLR-2, TLR-4, TNF-a, Zymosan

\section{Background}

Melanoma is a skin malignancy which develops from abnormal melanocytes and usually has a low response to conventional therapies [1]. It is a major cause of death in patients with skin cancer and approximately 55,000 deaths from melanoma were reported in 2012 [2]. The

\footnotetext{
* Correspondence: emortaz@gmail.com

${ }^{2}$ Department of Immunology, Faculty of Medicine, ShahidBeheshti University

of Medical Sciences, Tehran, Iran

${ }^{3}$ Division of Pharmacology, Utrecht Institute for Pharmaceutical Sciences,

Faculty of Sciences, Utrecht University, Utrecht, the Netherlands

Full list of author information is available at the end of the article
}

prevalence of the disease has increased alarmingly in recent years although the reasons for this are not well understood [3]. Metastatic melanoma has a median survival time of less than 1 year and there is no effective FDA-approved therapy [1]. Melanoma cells usually express self-antigens [4] which are not recognized by the host immune cells. In recent years, our knowledge and understanding of the melanoma has been advanced by the discovery of some of its specific antigens [5].

Multiple pathways are involved in both the priming and effector phases of melanoma rejection. Studies in 
animal models of melanoma showed a requirement for $\mathrm{CD} 4+\mathrm{T}$ cells in the priming phase of tumor immunotherapy [6]. Recent attention has focused on drugs that regulate the immune response to cancer cells. For example, cytokines such as IL-2 and IFN- $\alpha$ are used to reduce tumor invasion in the skin [7]. Toll-like receptors (TLRs) recognize pathogen associated molecular patterns (PAMPs) during infection and play a significant role in innate and adoptive immunity of diseases. TLRs are expressed on human cancer cells and TLR-based therapies have been evaluated as anti-cancer immunotherapies [8-10].

For many years, herbal and natural agents have been used for the prevention and treatment of cancers. The interest in natural remedies as anticancer agents has arisen due to the increased number of cancer patients and the significant side effects of synthetic chemotherapy agents [11]. Zymosan is a structural component of yeast cell wall which is rich in $\beta$-glucan and mannan and can bind to TLR2 on inflammatory cells. Consequently, it has been used to study the immune responses to TLR2 activation [12, 13]. Moreover, zymosan interacts with dectin-1 receptors on macrophages to stimulate the release of pro-inflammatory mediators and to modulate TLR expression and function [12, 14, 15]. We hypothesized that zymosan would attenuate melanoma growth and so we assessed the therapeutic effect of zymosan in an in vivo mouse model of melanoma. In the current study the effect of Zymosan A derived from Saccharomyces cerevisiae on serum TNF- $\alpha$ expression and on TLR2 and 4 genes expression in peritoneal macrophages and on melanoma growth progression was investigated.

\section{Methods}

\section{Animals and reagents}

6-8 week old female C57BL/6 mice (Razi Vaccine and Serum Research Institute, Karaj, Iran, average weight = $18 \pm 1.1 \mathrm{~g}$, healthy, drug-naive) were kept at $20^{\circ} \mathrm{C}$ with a relative humidity of $55 \pm 10 \%$ and $12 \mathrm{~h}$ light/dark cycles. Mice were randomly divided into 4 groups of 5 animals each:

i) Group Z: healthy mice receiving $10 \mu \mathrm{g}$ zymosan intraperitoneally (i.p.) $(n=5)$,

ii) Group M: tumor-induced mice receiving normal saline (i.p.) $(n=5)$,

iii) Group ZM: tumor-induced mice receiving $10 \mu \mathrm{g}$ zymosan i.p. $(\mathrm{n}=5)$,

iv) Group C: healthy mice receiving normal saline (i.p.) as controls $(n=5)$.

Animals were acclimatized to the environment for 1 week prior to the start of the study. Standard pellet food and tap water were provided ad libitum. For preparation of tumor tissues we had to $\mathrm{CO} 2$-euthanized all mice in the current study.

\section{Tumor induction}

The B16F10 melanoma cell line (Pasteur institute, Tehran, Iran) were incubated in RPMI medium (Gibco, Grand Island, NY, USA) containing $10 \%$ FBS at $37{ }^{\circ} \mathrm{C}$ and $5 \% \mathrm{CO}_{2}$. Melanoma was induced by subcutaneous injection of $1 \times 10^{6}$ B16F10 cells into the shaved lateral left flank of each mouse. Tumors were successfully induced in all injected mice. All observations were done performed every other day by one observer until establishment of a palpable tumor in each mouse. After successful tumor induction, the measurements were taken every day using the caliper. Tumor sizes never have been exceeded $1.5 \mathrm{~cm}$ in diameter according to the IACUC recommendations. In addition, the behavioral and clinical changes in mice such as notable reduction in food uptake, reduced mobility, lethargy and wound or necrosis problems of mice were monitored to exclude any mice exhibiting these characteristics. Regular monitoring of the mice did not reveal any unexpected deaths or severe clinical signs.. In addition to physical examinations we also performed histopathologic evaluations to confirm the establishment of subcutaneous melanoma. Histopathological sections prepared from tumor were investigated by two dermatopathologists. Mitotic rate/index, vascular invasion, lymphocyte infiltration, necrosis and hemorrhage were determined in a blinded manner.

\section{Zymosan preparation}

Zymosan A from Saccharomyces cerevisiae (Biosynth International Inc., Itasca, IL, USA) was stored at $-20{ }^{\circ} \mathrm{C}$ prior to use. Mice were injected with $10 \mu \mathrm{g}$ zymosan (groups $\mathrm{Z}$ and $\mathrm{ZM}$ ) daily i.p. for four consecutive days commencing 15 days after tumor-cells were injected.

\section{Tumor growth}

Tumor size was measured by carefully dissecting out and weighting the tumor tissue after $\mathrm{CO}_{2}$-induced euthanization of the mice.

\section{Cell viability and proliferation assay}

MTT was used to investigate lymphocyte viability. In brief, splenocytes were isolated from healthy mice. RMPI 1640 medium supplemented with 10\% FBS and antibiotics used as culture medium. $1 \times 10^{5}$ cells were seeded into the wells of two 96-well plates containing various concentrations of zymosan $(0-100 \mu \mathrm{g} / \mathrm{ml})$ and were incubated at $37{ }^{\circ} \mathrm{C}$ and $5 \% \mathrm{CO}_{2}$ for $72 \mathrm{~h}$. Cells from one plate were counted using trypan blue. Then, MTT was added into each well of the other plate and incubated for a further $4 \mathrm{~h}$. $150 \mu \mathrm{l}$ DMSO was added to stop the 
reaction and the optical density was read at $570 \mathrm{~nm}$ using an ELISA plate reader.

\section{Cytokine measurement}

Blood was collected from each mouse by heart puncture. Sera was isolated by centrifugation and the levels of TNF- $\alpha$ measured using a Bio-PlexPro ${ }^{\text {in }}$ Mouse Cytokine, Chemokine and Growth Factor Assay (Bio-Rad, Richmond, CA, USA) according to the manufacturer's instructions.

\section{Peritoneal macrophage isolation}

At the end of the 4-days treatment with zymosan or saline, mice were euthanized and peritoneal cells harvested by washing the peritoneal cavity with $10 \mathrm{ml}$ of ice-cold toxin-free PBS containing 3\% fetal calf serum. Cells were centrifuged at $300 \times \mathrm{g}, 4{ }^{\circ} \mathrm{C}$ for $10 \mathrm{~min}$ and suspended in $1 \mathrm{ml}$ complete DMEM medium supplemented with $10 \%$ FBS. Cells were counted using a haemocytometer and $3 \times 10^{6}$ cells were cultured on 6 well plates at $37{ }^{\circ} \mathrm{C}, 5 \%$ $\mathrm{CO}_{2}$ for $2 \mathrm{~h}$ to allow macrophages to adhere to the plates. Non-adherent cells were removed by washing the wells with cold sterile PBS. Cell viability was assessed by trypan blue staining. Macrophages were subsequently suspended in DMEM containing 10\% FBS.

\section{RNA isolation and cDNA synthesis}

Total RNA was isolated using TRIzol according to the manufacturer's instructions (Invitrogen, Carlsbad, CA, USA). The quantity and purity of RNA was measured by nanodrop (NanoDrop ND-1000; NanoDrop Technologies, Wilmington, DE, USA). RNA samples were transcribed to cDNA using an Intron MaximeRT premix kit (Intronbio, South Korea) according to the manufacturer's instructions. The synthetized cDNA was kept at $-20{ }^{\circ} \mathrm{C}$ prior to use.

\section{Real-time quantitative PCR (RT-qPCR)}

Quantitative evaluation of target genes expression was performed using a SYBR Green I based kit $\left(\mathrm{SYBR}^{\circ}\right.$ Premix Ex $\mathrm{Taq}^{\mathrm{mm}}$ II TliRNaseH Plus, TaKaRa Bio, Shiga,
Japan) in a Rotor-Gene Q real time PCR machine (Qiagen, Hilden, Germany). Previously published primer pairs for target genes and the reference gene are shown in Table 1 [16-19]. $20 \mu \mathrm{l}$ reaction mixtures were prepared in thin-walled PCR tubes as follows for each gene in triplicate: $10 \mu \mathrm{l} \mathrm{TaKaRa}$ qPCR master mix, $2 \mu \mathrm{l}$ of diluted cDNA template (dilution ratio was 1:10), $0.5 \mu \mathrm{l}$ of $10 \mathrm{mM}$ forward and reverse primers and $7 \mu \mathrm{l} \mathrm{dH}_{2} \mathrm{O}$ (sterile distilled water). After initial denaturation at $95^{\circ}$ $\mathrm{C}$ for $30 \mathrm{~s}, 40$ cycles [denaturation: $95{ }^{\circ} \mathrm{C}$ for $5 \mathrm{~s}$ and annealing and extension $\left(60{ }^{\circ} \mathrm{C}\right.$ for $\left.\left.30 \mathrm{~s}\right)\right]$ of PCR was performed. A melting curve analysis was performed using a temperature range between 60 and $92{ }^{\circ} \mathrm{C}$.

\section{Statistical analysis and comparative $\mathrm{Ct}$ method}

The effect size was predicted to be at least $50 \%$ which together with power and significance levels of $95 \%$ and 0.05 , respectively gave a total sample size of 20 mice $(n$ $=5$ for each group). Mann-Whitney $U$ test and linear regression analysis were performed using MedCalc version 12 (MedCalc Software, Ostend, Belgium) on the raw data and data presented as means \pm S.D. Alpha values were set at 0.05 and $P$-values $<0.05$ were considered as significant. Bonferroni's correction was used where multiple comparisons were made. We employed the delta delta $\mathrm{Ct}(\Delta \Delta \mathrm{Ct})$ method to calculate the relative expression of target genes [20]. The fold change of relative target gene expression was calculated by first normalization of the Ct (threshold cycle) value of the gene of interest relative to reference gene followed by the subtraction of the delta $\mathrm{Ct}$ value of treated samples from the delta $\mathrm{Ct}$ value of un-treated samples (control group). The data was presented using a $\log _{2}$ scale to ensure that similar up or down fold-changes gave a similar change above and below the $\mathrm{X}$ axis.

\section{Results}

Zymosan inhibited melanoma progression

Melanoma growth was confirmed by histopathologic evaluation of the skin tumors of mice (Fig. 1). Moderate pigmentation (yellowish-brown pigments) indicating the

Table 1 Primer sequences were used at present study

\begin{tabular}{|c|c|c|c|c|}
\hline Gene Symbol & & Sequence $\left(5^{\prime}-3^{\prime}\right)$ & Amplicon Size (bp) & Reference \\
\hline \multirow[t]{2}{*}{ GAPDH } & Sense & TGTTCCTACCCCCAATGTGT & 138 & Lukacs et al. [16] \\
\hline & Antisense & GGTCCTCAGTGTAGCCCAAG & & \\
\hline \multirow[t]{2}{*}{ TLR2 } & Sense & CCAAGAGGAAGCCCAAGAAAG & 51 & Matsushima et al. [17] \\
\hline & Antisense & AGGCATCATAGCAAACGTCCC & & \\
\hline \multirow[t]{2}{*}{ TLR4 } & Sense & GGACTCTGATCATGGCACTG & 101 & Ellett et al. [18] \\
\hline & Antisense & CTGATCCATGCATTGGTAGGT & & \\
\hline \multirow[t]{2}{*}{ TNF-a } & Sense & GCACCACCATCAAGGACTCAA & 51 & Auerbuch et al. [19] \\
\hline & Antisense & TCGAGGCTCCAGTGAATTCG & & \\
\hline
\end{tabular}




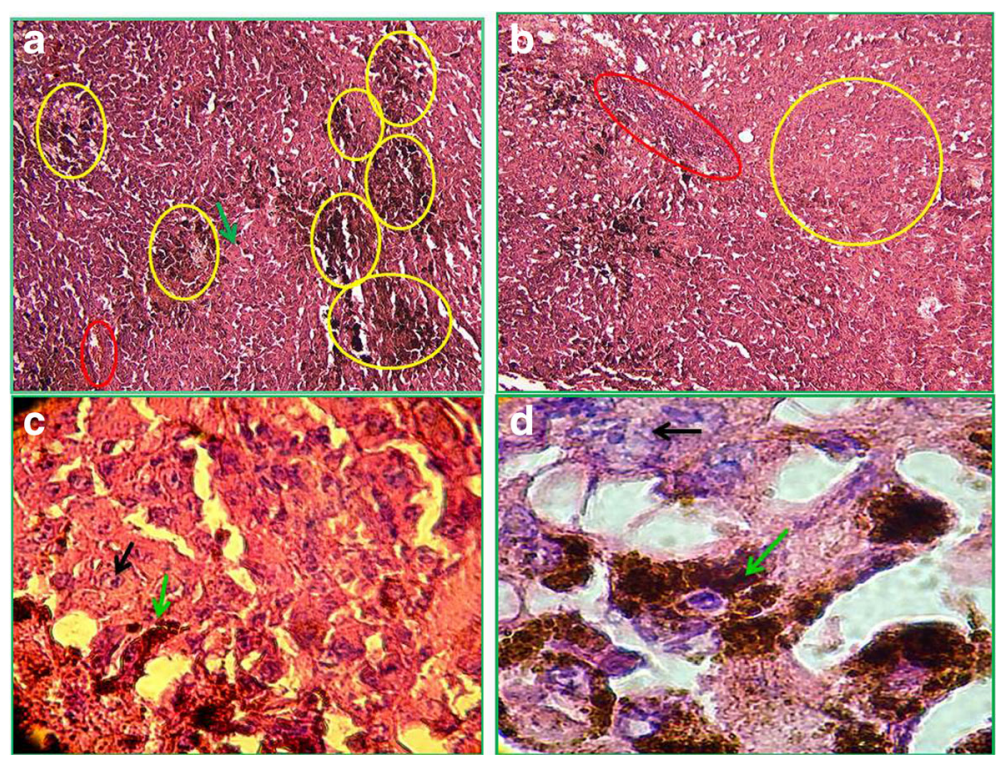

Fig. 1 Histopathologic sections obtained from melanoma tumor autopsy in mouse stained with H\&E (10-100 x magnifications). Representative histological analysis of tumor tissue from melanoma-bearing mice $(n=5)$. In panel a (10x magnification) the yellow circles indicate areas of intensive melanin pigmentation, a red circle indicates an area of hemorrhage and a green arrow highlights an invasive mitotic melanocyte. Its condensed genetic material (chromatin) indicates this as being mitotic. In panel b (10x magnification) the yellow circle shows an area containing many mitotic melanocytes and the neighboring red box area shows vascular invasion by some of the invasive melanocytes. In panel $\mathbf{c}$ (40x magnification) the upper black arrow shows a large mitotic melanocyte (with segmented chromatin and genetic material) and the lower green arrow shows melanin pigmentation (dark brown areas). In panel d (100x magnification) the upper black arrow shows a large mitotic melanocyte (with purple-stained genetic material) and the lower green arrow shows melanin pigmentation (dark brown area). All mice showed similar melanoma features

presence of melanin was observed in the hematoxylin and eosin (H\&E)-stained sections and intense pigmentation areas were observed in the nests of tumor melanocytes (Fig. 1a). Vascular invasion and slight hemorrhage were also observed but no lymphocyte infiltration was found (Fig. 1b). The mean mitotic rate was 11 mitoses/ $\mathrm{mm}^{2}$ (Fig. 1b). Mitotic morphology of nuclear chromatin and abnormal spindle-shaped invasive melanocytes were also observed in tumor tissue (Fig. $1 \mathrm{~b}$ and d). The presence of large mitotic melanocytes and of melanin pigmentation is shown at increasingly levels of magnification (Fig. 1c and d) in response to tumor induction. The mean weight of tumor in the zymosan-treated group (group $\mathrm{ZM}$ ) was significantly lower than in the untreated group $(\mathrm{M})(P<0.05)$ (Fig. 2).

\section{Zymosan induced mRNA expression and serum levels of TNF-a}

Mice in the zymosan group $(\mathrm{Z})$ had significantly greater serum TNF- $\alpha$ than any other group $(P<0.05)$ (Fig. 3). In

\section{a}

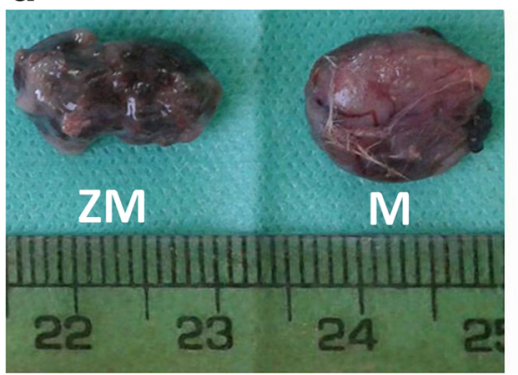

b

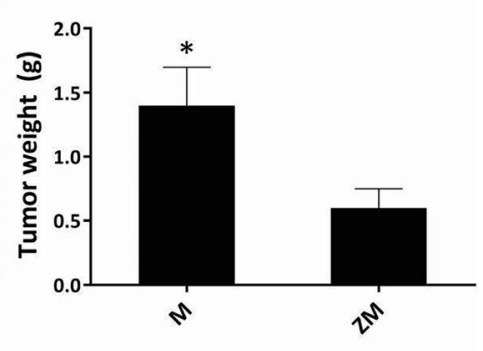

Fig. 2 Effect of therapeutic zymosan treatment on melanoma weight and size in melanoma-bearing mice. Representative pictures showing tumor size in melanoma-bearing (M) mice and the effect of therapeutic treatment with zymosan (10 $\mu \mathrm{g}$, i.p.) in melanoma-bearing (ZM) mice (a). The results are presented graphically as means \pm SD for all 5 animals in each group $(\mathbf{b})$. ${ }^{*} P<0.05$ compared with tumor size in $M$ mice. ZM indicates melanoma-bearing zymosan-treated mice 


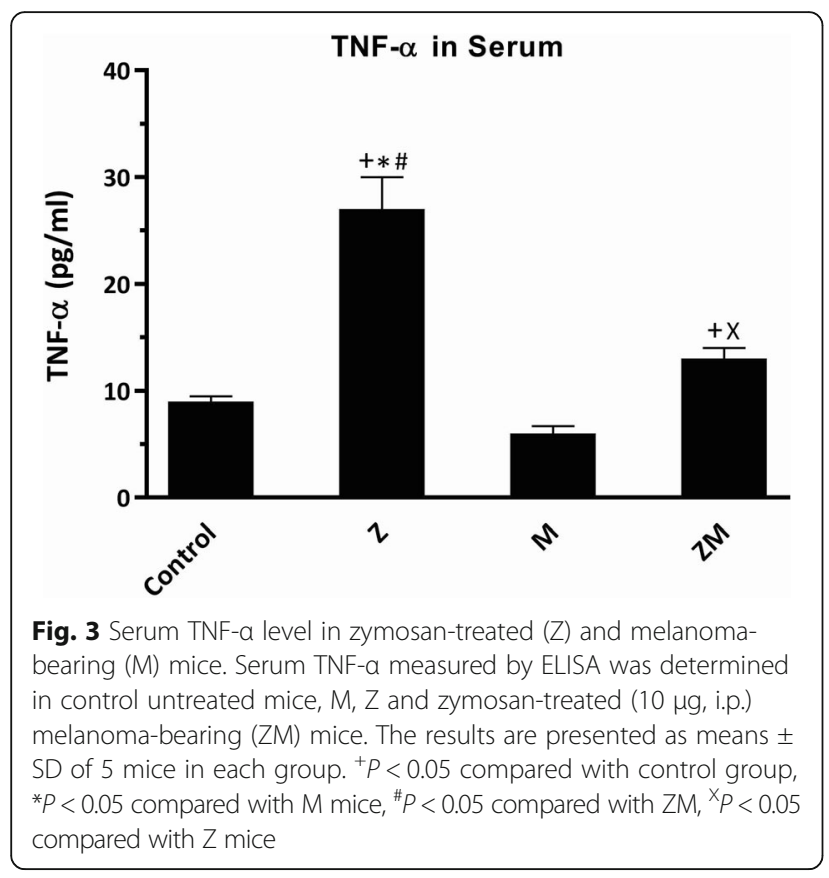

contrast, serum TNF- $\alpha$ levels in the melanoma-bearing mice $(\mathrm{M})$ were not significantly different from levels seen in control animals (C) (Fig. 3). Serum TNF- $\alpha$ levels in the zymosan-treated melanoma (ZM) group were elevated compared to those observed in the $C$ and $M$ groups (Fig. 3).
TNF- $\alpha$ mRNA levels in peritoneal macrophages from melanoma-bearing mice $(\mathrm{M})$ were decreased compared to control animals but were significantly elevated in zymosan-treated control animals $(\mathrm{Z})$ and in zymosantreated melanoma-bearing animals (ZM) (all $P<$ 0.05)(Fig. 4, Tables 2 and 3). The expression of TNF- $\alpha$ mRNA in peritoneal macrophages from $\mathrm{ZM}$ animals was intermediate between that in $\mathrm{Z}$ and $\mathrm{M}$ animals with a significant difference in expression between values from the $\mathrm{M}$ and $\mathrm{Z}$ alone groups.

\section{Zymosan upregulated TLR-2 and TLR-4 gene expression} Melanoma growth was associated with a significant reduction in TNF- $\alpha$, TLR-2 and TLR-4 mRNA expression in peritoneal macrophages compared to that in control mice $(P<0.05)$. TNF- $\alpha$ mRNA expression in melanomabearing mice $(\mathrm{M})$ was reduced by $83 \%$ compared to control mice while TLR- 4 and TLR-2 mRNA expression was suppressed by $70 \%$ and $35 \%$, respectively compared to control mice (Fig. 4, Tables 2 and 3). In contrast, zymosan significantly induced TNF- $\alpha$ and TLR-2 mRNA expression in both healthy $(\mathrm{Z})$ animals and in melanomabearing (ZM) animals. The expression of TLR-2 mRNA in the ZM mice (Fig. 4, Tables 2 and 3) was intermediate between that in the $Z$ and $M$ animals. The mRNA level of TLR-4 in $Z$ and $M$ mice followed the same pattern seen for TNF- $\alpha$ and TLR2 (Fig. 4, Tables 2 and 3). TLR4 mRNA expression in the ZM mice was no different from

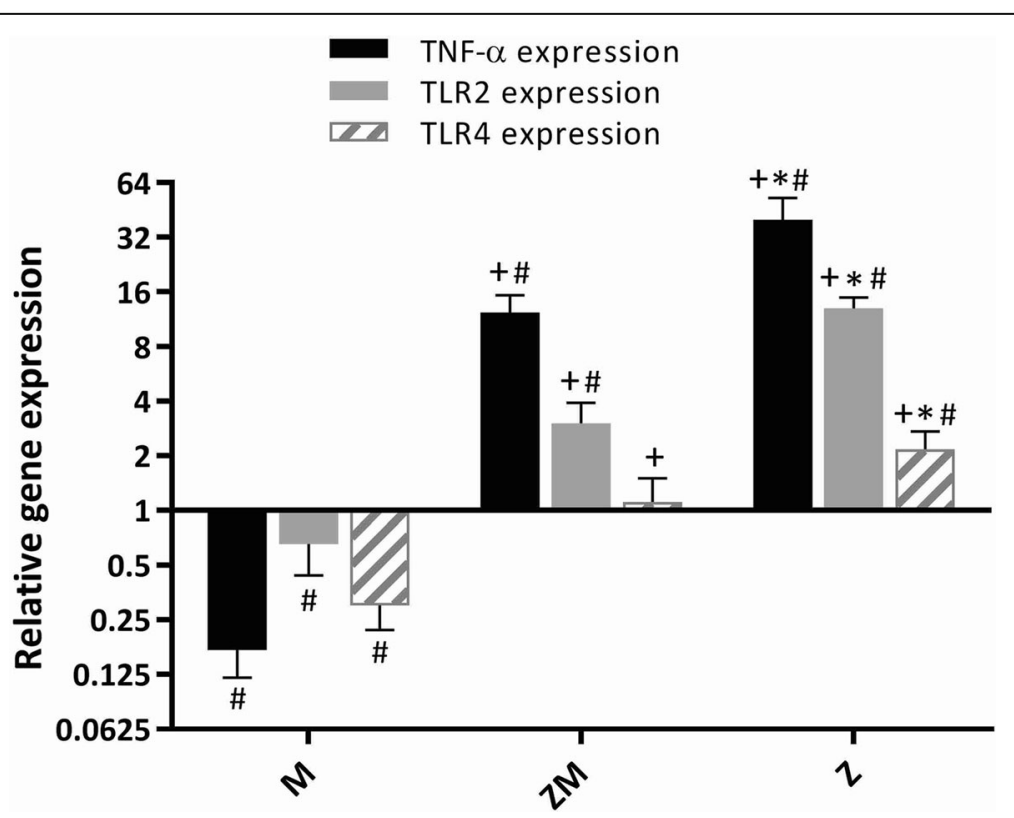

Fig. 4 Effect of zymosan treatment (Z) on TNF-a, TLR-2 and TLR-4 genes expression in mouse peritoneal macrophages in melanoma-bearing (M) mice. The expression of TNF-a (black bars), TLR-2 (grey bars) and TLR-4 (lined bars) mRNA in M, Z and zymosan-treated (10 $\mu$ g, i.p.) melanomabearing (ZM) mice was determined relative to that in control mice. Results are presented as means \pm SD of $n=5$ animals per group. ${ }^{+} P<0.05$ compared with M mice, ${ }^{*} P<0.05$ compared with ZM mice, ${ }^{\# P}<0.05$ compared with control mice 
Table 2 Significance values of TNF-a, TLR-2 and TLR-4 genes expression between groups

\begin{tabular}{llll}
\hline Comparator groups & \multicolumn{2}{l}{ Target genes } \\
\cline { 2 - 4 } & TNF- $a$ & TLR-2 & TLR-4 \\
\hline M/C & 0.002 & 0.0055 & 0.002 \\
ZM/C & 0.0018 & 0.0019 & 0.137 \\
Z/C & 0.0017 & 0.0019 & 0.002 \\
M/ZM & 0.0017 & 0.00197 & 0.00196 \\
M/Z & 0.00167 & 0.0018 & 0.00194 \\
ZM/Z & 0.00196 & 0.00197 & 0.0025
\end{tabular}

$C$ control untreated mice, $M$ melanoma-bearing mice, $Z$ zymosan-treated mice, $Z M$ zymosan-treated melanoma-bearing mice. $P$ values are reported as MannWhiney $\mathrm{U}$ tests

that seen in control mice being intermediate between that seen in $\mathrm{M}$ and $\mathrm{Z}$ mice (Fig. 4, Tables 2 and 3).

\section{Zymosan stimulates splenocyte proliferation}

Zymosan induced a concentration-dependent increase in splenocyte viability (Fig. 5a) and proliferation (Fig. 5b). Splenocyte viability in the $0.1,1$ and $10 \mu \mathrm{g} / \mathrm{ml}$ zymosantreated cells was significantly higher than in the control media-treated cells $(P<0.05)$. The viability reached a maximum at $1 \mu \mathrm{g} / \mathrm{ml}$ zymosan treatment before being reduced at the highest concentrations tested. The viability at a high concentration of zymosan $(100 \mu \mathrm{g} / \mathrm{ml})$ tested was similar to that observed in the control (untreated) cells (Fig. 5a). Similar results were observed with the splenocyte proliferation assays. Zymosan, at all concentrations, induced splenocyte proliferation compared to negative control cells $(P<0.05)$. However, at the higher zymosan concentrations of 10 and $100 \mu \mathrm{g} / \mathrm{ml}$ splenocyte proliferation was decreased compared to the maximal effect seen at $1 \mu \mathrm{g} / \mathrm{ml}$ (Fig. 5b). There was a strong positive correlation between viability and proliferation rates of splenocytes (linear regression, $R^{2}=0.77$ ) (Fig. 5c).

\section{Discussion}

This study demonstrated that therapeutic treatment with zymosan attenuated melanoma growth in vivo. This therapeutic response was associated with an up-regulation of TNF- $\alpha$ and TLR-2/4 gene expression along with

Table 3 Fold change values of TNF-a, TLR-2 and TLR-4 genes expression relative to control group

\begin{tabular}{llll}
\hline Groups & \multicolumn{3}{l}{ Target genes } \\
\cline { 2 - 4 } & TNF- $a$ & TLR-2 & TLR-4 \\
\hline M & $0.17 \pm 0.05$ & $0.66 \pm 0.22$ & $0.3 \pm 0.08$ \\
ZM & $12.27 \pm 3.07$ & $3.02 \pm 0.9$ & $1.11 \pm 0.4$ \\
Z & $39.85 \pm 12.75$ & $12.95 \pm 1.94$ & $2.18 \pm 0.54$ \\
\hline
\end{tabular}

$M$ melanoma-bearing mice, $Z$ zymosan-treated mice, $Z M$ zymosan-treated melanoma-bearing mice. Data were presented as means \pm standard deviation splenocyte viability and proliferation. We hypothesize that these immunomodulatory events are associated with zymosan-induced tumor inhibition.

The major constituent of zymosan is $\beta$-glucan which is responsible for anti-tumor activity of zymosan [21]. Tumor-inhibition by oxidized-zymosan (OX-ZYM), which is mainly composed of $1,3-\beta$ - and $1,6-\beta$-glucan was significantly greater than that achieved with reduced and hydrolyzed OX-ZYM in which its 1,6- $\beta$-glucan moiety was removed. This indicates the central role of $(1,6)$-branched $(1,3)$ - $\beta$-glucans in inhibiting tumor growth [21].

The antitumor effect of zymosan was first studied in sarcoma-bearing mice in 1957 by Bradner et al., who reported that zymosan promoted tumor depletion by utilizing a host defense response [22]. Subsequent studies have confirmed that the major anti-tumor activities of glucans are due to their effects on the immune system rather than a direct effect on tumor cells. Our results also showed a considerable anti-tumor effect when administering zymosan therapeutically to melanoma-bearing mice. The mean tumor weight being significantly reduced by $\sim 50 \%$ in zymosan-treated melanoma-bearing mice compared to non-treated control mice. Future studies will examine the potential of zymosan co-treatment with other anti-cancer agents to completely suppress melanoma survival.

A previous study reported that zymosan $(100 \mu \mathrm{g} / \mathrm{mL})$ could induce a $300 \%$ greater production of TNF- $\alpha$ from murine macrophages compared to that elicited by LPS $(100 \mathrm{ng} / \mathrm{mL})$ [14]. Furthermore, a synthetic $\beta-(1 \rightarrow 3)$ gluco-hexose drives macrophages towards an M1-like phenotype and enhances the production of numerous inflammatory cytokines such as IL- $1 \alpha$, IL-1 $\beta$, IL-12, IL16, IL-17, IL-23, TNF- $\alpha$ and IFN- $\gamma$ [23]. $\beta-(1,3)-(1,6)-$ glucan derived from baker's yeast also could induce similar levels of TNF- $\alpha$, IL-8 and IL- 6 production from whole blood cells as seen with LPS [24]. These observations are in agreement with our previous study, where zymosan promoted the expression of IL- 6 and IL- $1 \beta$ in melanoma-bearing mice and enhanced the phagocytic ability of macrophages [13].

Moreover, in the present study, TNF- $\alpha$ was strongly up-regulated in zymosan-administered mice in comparison to other experimental groups at both the protein and mRNA level. TNF- $\alpha$ protein production and release can be due to strong induction of TLR-2 by zymosan stimulation. This was associated with a significant reduction in tumor weight indicating an impact of zymosan on the immune response against tumor cells. The precise mechanism for this effect is unclear although in a previous study it was reported that oral zymosan treatment of subcutaneous S180 tumor-bearing mice enhanced the immune response via having a significant antioxidant effect [25]. Further studies utilizing TNF- $\alpha$ cell-specific conditional knockout mice or anti-TNF 

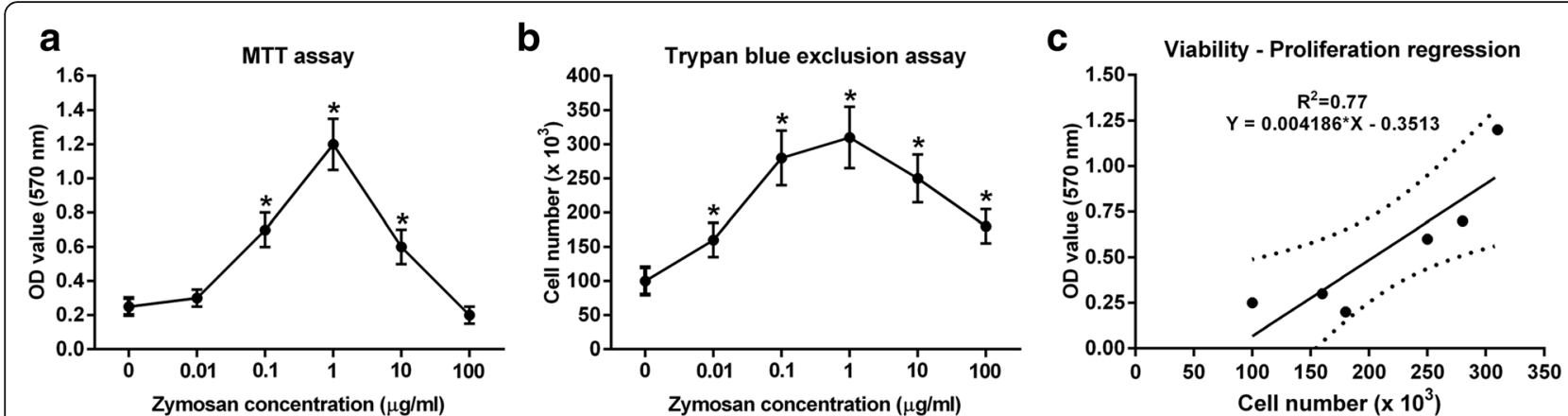

Fig. 5 The viability and proliferation of murine splenocytes ex-vivo is increased concentration-dependently by zymosan treatment. Panel a represents the viability of splenocytes after $72 \mathrm{~h}$ treatment with different concentrations of zymosan as determined by MTT assay. Panel $\mathbf{b}$ represents number of splenocytes as measured by trypan blue exclusion assay when treated for $72 \mathrm{~h}$ with increasing concentrations of zymosan. Panel c represents the correlation between splenocyte viability and proliferation. The data are reported as the means \pm SD of at least 3 independent experiments. ${ }^{*} P<0.05$ compared with control splenocytes not treated with zymosan

mAbs will address the exact role of TNF- $\alpha$ in immune cell activation and tumor suppression in this model.

TLR2 and dectin-1, the major zymosan receptors [14], act co-operatively to detect microbial PAMPs [26, 27, 28]. Macrophages recognize $\beta$-glucan using TL2/4 and dectin-1 [23] and zymosan, acting through TLR2/4, can induce a similar level of NF-kB/AP-1 activity in HEK cells as seen with specific TLR-2 (Pam3CSK4) and TLR4 (LPS) ligands [14]. Zymosan $(\leq 100 \mu \mathrm{g} / \mathrm{mL})$ induces NF-кB/AP-1-related TLR-2 and TLR4 activity [14]. In our study we detected a significant increase in TLR4 mRNA in macrophages from zymosan-treated mice. In contrast, there is also a significant reduction in TLR-4 expression in melanoma-bearing mice, indicating a strong suppressor effect of melanoma on its level. The positive effect of zymosan on TLR-4 regulation could be due to two reasons: the feedforward effect of cytokines on TLR-4 (e.g. positive effect of IFN- $\gamma$ on TLR-4) and activation of macrophages. It was known that some cytokines promote TLR expression. IFN- $\gamma$ shows a stimulatory effect on TLR-2/4 expression via blocking the inhibitory cytokines and activating macrophages [29, 30]. Zymosan-like molecules or glucan compounds can induce release of IFN- $\gamma$ in macrophages $[23,31]$. Total crude extract of a strain of Saccharomyces cerevisiae composed of $\beta$-glucan, protein and lipid (similar to zymosan) could induce IL-10, IL-17 and IFN- $\gamma$ at low dose [31]. Zymosan itself can induce CD3-activated thymocytes and splenocytes to produce IFN- $\gamma[32]$.

In addition, activated macrophages have higher surface expression of TLR2 and 4 [29]. Activation of cell surface TLRs by ligand binding results in activation of both NF$\kappa \mathrm{B}$-dependent and interferon regulating factor (IRF)dependent signaling. Activation of these pathways leads to leukocyte recruitment and their immigration to sites of inflammation [33]. As a result, some anti-cancer therapies based on TLR-signaling are under development $[8,34]$.

Stimulation of TLRs-2, -3 and -4 results in the production of pro-inflammatory cytokines such as TNF $\alpha$, IL-1, IL-6 and G-CSF and chemokines [35]. These inflammatory mediators play an important role in tumor rejection by activating T cells [34]. For example, TNF- $\alpha$ enhances leukocyte recruitment to inflammatory sites and promotes infiltration of cytotoxic $\mathrm{T}$ cells into the tumor vicinity [8] and TLR2-mediated production of IL12 and TNF- $\alpha$ by macrophages results in NK cell activation and induction of the adaptive immune response [36, 37]. OM-174 a TLR-2/4 agonist together with BCG demonstrated anti-cancer activity through induction of TNF$\alpha$ [9], whilst krestin, a selective TLR-2 agonist, inhibits breast cancer in mice [10]. In our study, zymosan treatment significantly increased TLR-2 and TNF- $\alpha$ gene expression in macrophages and enhanced serum TNF- $\alpha$ levels. This was in direct contrast to the suppression of these genes by the presence of melanoma alone.

Beside the generally accepted apoptosis-inducing and anti-tumor activity of TNF- $\alpha$, it can also promote metastasis of tumor cells by inducing the chemokine receptors on the tumor cells particularly in late stage cancers [37]. However, recent studies have demonstrated the efficacy of TNF- $\alpha$ against melanoma [7, 38, 39]. TNF- $\alpha$ induces extravasation of erythrocytes and lymphocytes ending to hemorrhagic necrosis [37]. Moreover, TNF $\alpha$ targets tumor-associated vasculature by elimination of vascular lining and induction of hyper-permeability within tumor environment. These effects then provide better permeability of cytostatic drugs into the tumor milieu [37]. Recently, 5-aza an apoptosis-inducing agent with promising anti-melanoma effects was shown to act through the induction of TNF- $\alpha$ in melanoma tumor cells leading to caspase-dependent apoptosis [38]. Intra-tumoral administration of L19-TNF- $\alpha$, a combination anti-cancer 
therapy, showed significant anti-melanoma activity in a phase II clinical trial in patients with advanced stage metastatic melanoma [39]. The clinical effect was associated with TNF- $\alpha$-mediated extravasation of leukocytes, necrosis, hemorrhage and infiltration of cytotoxic CD8+ T cells into the tumor site [39]. Also, intra-tumoral administration of adenoviruses encoding IL-2 and TNF- $\alpha$ into B16 melanoma tumors showed anti-tumor activity in comparison to T-cell or control viral transfer alone [7].

Glucans and zymosan could exhibit a stimulatory and mitogenic effect on cytotoxic T cells such as NK cells, CD8+ $\mathrm{T}$ and macrophages [36, 40]. Zymosan at the doses between 1 and $100 \mu \mathrm{g} / \mathrm{mL}$ is mitogenic for rat thymocytes [41]. In a recent study zymosan stimulated the adaptive immune system by increasing peritoneal lymphocyte numbers as well as causing the proliferation of peripheral blood T- and B-cells [42]. Our results showing a mitogenic/proliferative activity of zymosan on murine splenocytes ex-vivo are in agreement with these findings. We observed a bell-shaped concentrationresponse curve on lymphocyte proliferation and viability. The reduction on proliferation and viability at the highest concentrations might reflect zymosan toxicity for lymphocytes at the highest concentrations studied.

Glucans also stimulate the production of interferons that activate NK cells which can directly kill tumor cells [36]. In addition, particulate $\beta$-glucans, like those in insoluble glucan part of zymosan, can prime cytotoxic Tlymphocytes and stimulate Th1 responses [43]. Zymosan particles were phagocytized by macrophages and changed their morphology to an activated form which produce more cytokines and promote T-cell activation and migration [36, 44]. Zymosan may also activate neutrophils through the CR3 receptor and induce superoxide production. Pre-treatment of neutrophils with TNF- $\alpha$ stimulates phagocytosis activity and superoxide production in response to activation by zymosan [36].

\section{Conclusion}

The success of a cancer immunotherapy is largely dependent upon the patient's immune system, tumor progression stage and the method, route and administration site. We evaluated TLR2, TLR4 and TNF- $\alpha$ mRNA expression in peritoneal macrophages and serum TNF- $\alpha$ protein levels at a single time-point after tumor induction and after therapeutic intervention with zymosan. Further studies on the dose- and time-course of zymosan anti-tumor effects and on its mechanism of action are required. Since intact zymosan is insoluble, it is important to either increase zymosan solubility or use more active components of zymosan that may require lower therapeutic doses to enhance the effective biological activity of zymosan. These limitations notwithstanding, our results indicate that zymosan effectively attenuates melanoma presence when dosed therapeutically in an animal model and may therefore be useful as an alternative or complementary therapy. This effect was associated with immune reprogramming but further studies are required to explore the exact effects of zymosan on immune cells activation.

\section{Abbreviations \\ CR3: Complement receptor 3; DMEM: Dulbecco's Modified Eagle's Medium; FBS: Fetal bovine serum; G-CSF: Granulocyte colony-stimulating factor; LPS: Lipopolysaccharide; MTT: 3-(4,5-dimethylthiazol-2-yl)-2,5- diphenyltetrazolium bromide; NF-kB: Nuclear Factor Kappa Beta; NK cells: Natural killer cells; PAMPs: Pathogen associated molecular patterns; RPMI: Roswell Park Memorial Institute; TLR: Toll-like receptor; TLR-2: Toll-like receptor 2; TNF-a: tumor necrosis factor a}

\section{Acknowledgements}

Ian M. Adcok is supported by Wellcome Trust grant 093080/Z/10/Z and by the NIHR Respiratory Disease Biomedical Research Unit at the Royal Brompton and Harefield NHS Foundation Trust and Imperial College London. The views expressed in this publication are those of the authors(s) and not necessarily those of the NHS, The National Institute for Health Research or the Department of Health.

Funding

Not applicable

\section{Availability of data and materials}

The datasets of present study can be available from the corresponding author upon request.

\section{Authors' contributions}

All authors contributed in idea and concept of the work. MT performed in-vivo and ex-vivo experiments. GV performed the qPCR experiments. GV and MT drafted the manuscript. EM supervised the experiments. All authors commented, edited and revised the text of the manuscript. The final version of the manuscript in its current form was seen and approved by all of the authors for the publication.

\section{Ethics approval}

All procedures involving animals and their care were based on instructions recommended by Institutional Animal Care and Use Committee (IACUC) and the local animal ethics committee of the University of Tehran. The local ethics committee approved the practical protocols used in this study. The treatment procedures and medical interventions are based on IACUC recommendations. The sample size (the number of mice) was least possible considering the statistics criteria.

Consent for publication

Not applicable

\section{Competing interests}

The authors declare that they have no competing interests.

\section{Publisher's Note}

Springer Nature remains neutral with regard to jurisdictional claims in published maps and institutional affiliations.

\footnotetext{
Author details

${ }^{1}$ Mycology Research Center, Faculty of Veterinary Medicine, University of Tehran, Tehran, Iran. 'Department of Immunology, Faculty of Medicine, ShahidBeheshti University of Medical Sciences, Tehran, Iran. ${ }^{3}$ Division of Pharmacology, Utrecht Institute for Pharmaceutical Sciences, Faculty of Sciences, Utrecht University, Utrecht, the Netherlands. ${ }^{4}$ Clinical Tuberculosis and Epidemiology Research Center, National Research Institute of Tuberculosis and Lung Diseases (NRITLD), Shahid Beheshti University of Medical Sciences, Tehran, Iran. ${ }^{5}$ Mycobacteriology Research Center (MRC), National Research Institute of Tuberculosis and Lung Diseases (NRITLD), Shahid Beheshti University of Medical Sciences, Tehran, Iran. ${ }^{6}$ Nutricia
} 
Research Centre for Specialized Nutrition, Utrecht, Netherlands. ${ }^{7}$ Airways Disease Section, National Heart and Lung Institute, Faculty of Medicine, Imperial College London, London, UK.

\section{Received: 25 November 2017 Accepted: 11 March 2018}

Published online: 22 March 2018

\section{References}

1. Bhatia S, Tykodi SS, Thompson JA. Treatment of metastatic melanoma: an overview. Oncology (Williston Park). 2009;23:488-96.

2. Stewart BW, Wild C. World Cancer report 2014. International Agency for Research on Cancer. Lyon: World Health Organization. 2014;505

3. Erdei E, Torres SM. A new understanding in the epidemiology of melanoma. Expert Rev Anticancer Ther. 2010;10:1811-23.

4. Barrow C, Browning J, MacGregor D, Davis ID, Sturrock S, Jungbluth AA Cebon J. Tumor antigen expression in melanoma varies according to antigen and stage. Clin Cancer Res. 2006;12:764-71.

5. Shepelin D, Korzinkin M, Vanyushina A, Aliper A, Borisov N, Vasilov R, Zhukov N, Sokov D, Prassolov V, Gaifullin N, et al. Molecular pathway activation features linked with transition from normal skin to primary and metastatic melanomas in human. Oncotarget. 2016;7:656-70.

6. Gajewski TF, Schreiber H, Fu YX. Innate and adaptive immune cells in the tumor microenvironment. Nat Immunol. 2013;14:1014-22

7. Siurala M, Havunen R, Saha D, Lumen D, Airaksinen AJ, Tahtinen S, CerveraCarrascon V, Bramante S, Parviainen S, Vaha-Koskela M, et al. Adenoviral delivery of tumor necrosis factor-alpha and Interleukin-2 enables successful adoptive cell therapy of immunosuppressive melanoma. Mol Ther. 2016;24: 1435-43.

8. Aalaei-Andabili SH, Basith S, Choi S, Rezaei N. Toll-Like Receptor Pathway and its Targeting in Treatment of Cancers. In: Rezaei N. (eds) Cancer Immunology. Berlin: Springer; 2015. p. 329-39.

9. Garay RP, Viens P, Bauer J, Normier G, Bardou M, Jeannin JF, Chiavaroli C. Cancer relapse under chemotherapy: why TLR2/4 receptor agonists can help. Eur J Pharmacol. 2007;563:1-17.

10. Lu H, Yang Y, Gad E, Wenner CA, Chang A, Larson ER, Dang Y, Martzen M, Standish $L$, Disis ML. Polysaccharide krestin is a novel TLR2 agonist that mediates inhibition of tumor growth via stimulation of CD8 T cells and NK cells. Clin Cancer Res. 2011;17:67-76.

11. Chinembiri TN, du Plessis LH, Gerber M, Hamman JH, du Plessis J. Review of natural compounds for potential skin cancer treatment. Molecules. 2014;19: 11679-721.

12. Sato M, Sano H, Iwaki D, Kudo K, Konishi M, Takahashi H, Takahashi T, Imaizumi H, Asai Y, Kuroki Y. Direct binding of toll-like receptor 2 to zymosan, and zymosan-induced NF-kappa B activation and TNF-alpha secretion are down-regulated by lung collectin surfactant protein a. J Immunol. 2003;171:417-25.

13. Taghavi M, Mortaz E, Khosravi A, Nikaein D, Barin A, Vahedi G, Shokri H. The efficacy of zymosan in pro-inflammatory cytokine production by peritoneal macrophages of melanoma-bearing mice. Comp Clin Pathol. 2016;25:825.

14. Walachowski S, Tabouret G, Foucras G. Triggering Dectin-1-pathway alone is not sufficient to induce cytokine production by murine macrophages. PLoS One. 2016:11:e0148464

15. Hanashima S, Ikeda A, Tanaka H, Adachi Y, Ohno N, Takahashi T, Yamaguchi $Y$. NMR study of short $\beta(1-3)$-glucans provides insights into the structure and interaction with Dectin-1. Glycoconj J. 2014;31:199-207.

16. Lukacs RU, Memarzadeh $\mathrm{S}, \mathrm{Wu} \mathrm{H}$, Witte ON. Bmi-1 is a crucial regulator of prostate stem cell self-renewal and malignant transformation. Cell Stem Cell. 2010;7:682-93

17. Matsushima H, Yamada N, Matsue H, Shimada S. TLR3-, TLR7-, and TLR9mediated production of proinflammatory cytokines and chemokines from murine connective tissue type skin-derived mast cells but not from bone marrow-derived mast cells. J Immunol. 2004;173:531-41.

18. Ellett JD, Evans ZP, Atkinson C, Schmidt MG, Schnellmann RG, Chavin KD. Toll-like receptor 4 is a key mediator of murine steatotic liver warm ischemia/reperfusion injury. Liver Transpl. 2009;15:1101-9.

19. Auerbuch V, Brockstedt DG, Meyer-Morse N, O'Riordan M, Portnoy DA. Mice lacking the type I interferon receptor are resistant to listeria monocytogenes. J Exp Med. 2004;200:527-33.

20. Livak KJ, Schmittgen TD. Analysis of relative gene expression data using real-time quantitative PCR and the 2(-Delta Delta C(T)) method. Methods. 2001;25:402-8.
21. Ohno N, Miura T, Miura N, Adachi Y, Yadomae T. Structure and biological activities of hypochlorite oxidized zymosan. Carbohydr Polym. 2001:44:339-49.

22. Bradner WT, Clarke DA, Stock CC. Stimulation of host defense against experimental cancer. I. Zymosan and sarcoma 180 in mice. Cancer Res. 1958;18:347-51

23. Li X, Wang J, Wang W, Liu C, Sun S, Gu J, Wang X, Boraschi D, Huang Y, Qu D. Immunomodulatory activity of a novel, synthetic beta-glucan (beta-glu6) in murine macrophages and human peripheral blood mononuclear cells. PLoS One. 2013;8:e80399.

24. Noss I, Doekes G, Thorne PS, Heederik DJ, Wouters IM. Comparison of the potency of a variety of beta-glucans to induce cytokine production in human whole blood. Innate Immun. 2013;19:10-9.

25. Liu XL, Lin N, Zan D, Yuan JJ, Cai DL. Effect of zymosan on antioxidant and immune function of S180 tumor-bearing mice. Cell Biochem Biophys. 2011; 60:225-9.

26. Gantner BN, Simmons RM, Canavera SJ, Akira S, Underhill DM. Collaborative induction of inflammatory responses by dectin-1 and toll-like receptor 2. J Exp Med. 2003;197:1107-17.

27. Taghavi M, Khosravi A, Mortaz E, Nikaein D, Athari SS. Role of pathogenassociated molecular patterns (PAMPS) in immune responses to fungal infections. Eur J Pharmacol. 2017:808:8-13.

28. Mortaz E, Adcock IM, Tabarsi P, Masjedi MR, Mansouri D, Velayati AA, Casanova JL, Barnes PJ. Interaction of pattern recognition receptors with Mycobacterium tuberculosis. J Clin Immunol. 2015;35(1):1-10.

29. Hu X, Chakravarty SD, Ivashkiv LB. Regulation of interferon and toll-like receptor signaling during macrophage activation by opposing feedforward and feedback inhibition mechanisms. Immunol Rev. 2008;226:41-56.

30. O'Mahony DS, Pham U, lyer R, Hawn TR, Liles WC. Differential constitutive and cytokine-modulated expression of human toll-like receptors in primary neutrophils, monocytes, and macrophages. Int J Med Sci. 2008;5:1-8.

31. Pengkumsri N, Sivamaruthi BS, Sirilun S, Peerajan S, Kesika P, Chaiyasut K, Chaiyasut $C$. Extraction of $\beta$-glucan from Saccharomyces cerevisiae: comparison of different extraction methods and in vivo assessment of immunomodulatory effect in mice. Food Sci Technol (Campinas). 2017;37: 124-30.

32. Zimmermann C, Weber A, Mausberg AK, Kieseier BC, Hartung HP, Hofstetter $\mathrm{HH}$. T cell activation status determines the cytokine pattern induced by zymosan and bacterial DNA both in thymocytes and splenocytes. Clin Exp Immunol. 2013;172:245-53.

33. Akira S, Takeda K. Toll-like receptor signalling. Nat Rev Immunol. 2004:4:499-511.

34. Karki K, Pande D, Negi R, Khanna S, Khanna RS, Khanna HD. Linking Toll-Like Receptors Signaling to Oxidative Damage: Potential Role in Cancer Therapy. In: Rani V., Yadav U. (eds) Free Radicals in Human Health and Disease. New Delhi: Spring; 2015. p. 323-34.

35. Goto Y, Arigami T, Kitago M, Nguyen SL, Narita N, Ferrone S, Morton DL, Irie RF, Hoon DS. Activation of toll-like receptors 2, 3, and 4 on human melanoma cells induces inflammatory factors. Mol Cancer Ther. 2008;7: 3642-53.

36. Bohn JA, JN BM. ( $1 \rightarrow 3)-\beta-D-$ glucans as biological response modifiers: a review of structure-functional activity relationships. Carbohydr Polym. 1995; 28:3-14.

37. van Horssen R, Ten Hagen TL, Eggermont AM. TNF-alpha in cancer treatment: molecular insights, antitumor effects, and clinical utility. Oncologist. 2006;11:397-408.

38. Noguchi S, Mori T, Igase M, Mizuno T. A novel apoptosis-inducing mechanism of 5-aza-2'-deoxycitidine in melanoma cells: demethylation of TNF-alpha and activation of FOXO1. Cancer Lett. 2015;369:344-53.

39. Danielli R, Patuzzo R, Di Giacomo AM, Gallino G, Maurichi A, Di Florio A, Cutaia O, Lazzeri A, Fazio C, Miracco C, et al. Intralesional administration of L19-IL2/L19-TNF in stage III or stage IVM1a melanoma patients: results of a phase II study. Cancer Immunol Immunother. 2015;64:999-1009.

40. Navarro-Xavier RA, Newson J, Silveira VL, Farrow SN, Gilroy DW, Bystrom J. A new strategy for the identification of novel molecules with targeted proresolution of inflammation properties. J Immunol. 2010;184:1516-25.

41. Sandula J, Machova E, Hř́balová V. Mitogenic activity of particulate yeast $\beta$ $(1 \rightarrow 3)$-D-glucan and its water-soluble derivatives. Int J Biol Macromol. 1995; 17:323-6.

42. Newson J, Stables M, Karra E, Arce-Vargas F, Quezada S, Motwani M, Mack M, Yona S, Audzevich T, Gilroy DW. Resolution of acute inflammation bridges the gap between innate and adaptive immunity. Blood. 2014;124: 1748-64. 
43. Qi C, Cai Y, Gunn L, Ding C, Li B, Kloecker G, Qian K, Vasilakos J, Saijo S, Iwakura $Y$, et al. Differential pathways regulating innate and adaptive antitumor immune responses by particulate and soluble yeast-derived beta-glucans. Blood. 2011;117:6825-36

44. Cohen HJ, Newburger PE, Chovaniec ME, Whitin JC, Simons ER. Opsonized zymosan-stimulated granulocytes-activation and activity of the superoxide-generating system and membrane potential changes. Blood. 1981;58:975-82.

Submit your next manuscript to BioMed Central and we will help you at every step:

- We accept pre-submission inquiries

- Our selector tool helps you to find the most relevant journal

- We provide round the clock customer support

- Convenient online submission

- Thorough peer review

- Inclusion in PubMed and all major indexing services

- Maximum visibility for your research

Submit your manuscript at www.biomedcentral.com/submit 